Revista Iberoamericana, Vol. LXXXIII, Núm. 258, Enero-Marzo 2017, 73-86

\title{
LA OBRA INVISIBLE DE EMILIO RENZI: LUGAR INCIERTO, TRADICIÓN CLANDESTINA
}

\author{
POR \\ Sergio Waisman \\ The George Washington University
}

\begin{abstract}
La tradición es como una huella, un rastro en la tierra, un rumbo que define la marcha: su clave es la localización. Boedo y Florida, para poner un ejemplo conocido, importan porque definen el lugar desde donde se escribe (y se lee). La literatura está situada, y por lo tanto la tradición es una posición en el doble sentido del término: un lugar y una actitud.
\end{abstract}

Piglia, "El lugar de Saer" 162

\section{INTRODUCCIÓN}

En la literatura de Ricardo Piglia frecuentemente se puede percibir otra literatura -clandestina e invisible- que coexiste con las historias a plena vista que se narran en los libros visibles que tenemos en nuestras manos. De la falsa atribución de autoría en Nombre falso, al diario fragmentado en Prisión perpetua, al Diario póstumo que el escritor escribe en vida, a la doble lectura requerida en Respiración artificial, a la isla imaginada en La ciudad ausente, a la postulación del último lector, al epílogo de Plata quemada y las notas en Blanco nocturno, Piglia trabaja el concepto de una creación invisible al lado de la visible, una duplicidad creadora que se concreta alrededor de la compleja figura de Emilio Renzi. En este ensayo propongo hacer una lectura de la obra (invisible) de Renzi que aparece -que es sugerida, implicada, proyectada en- la obra (visible) de Piglia, para así apuntar a ciertos aspectos claves de la conceptualización de Piglia sobre la tradición literaria argentina, y su relación con otra práctica invisible -con una práctica casi invisible, más bien: la escena casi invisible de la traducción.

¿Es posible que haya otra literatura, no publicada, sólo mencionada ocasionalmente en la literatura que sí existe? ¿O son las mismas las dos? ¿Podría esta ser también una búsqueda de esa otra literatura? ¿Cuál es la relación entre la literatura invisible 
de Renzi, en la literatura visible de Piglia, y la tradición clandestina y secreta de la Argentina? Y la traducción, en este contexto: ¿es una metáfora de esa otra literatura, o funciona-también-como una máquina creadora de esa otra literatura? Este ensayo busca algunas posibles respuestas a estas incertidumbres sobre la tradición y la traducción.

Empezamos con el ejemplo más notable del fenómeno de una obra invisible en Piglia: la novela de Renzi citada cerca del comienzo de Respiración artificial. En las primeras páginas de Respiración artificial se hace referencia a una novela de Emilio Renzi -La prolijidad de lo real- de la cual se cita la primera frase. El procedimiento borgeano de simular que un libro ya existe "y ofrecer un resumen, un comentario" (Borges 429) ${ }^{1}$ de ese libro, además de la cita visible de la primera frase de una novela que, salvo esa frase, suponemos apócrifa, sugiere el resto de las 200 páginas de esa novela. Suponemos apócrifa, digo, porque La prolijidad de lo real emerge como una novela casi invisible justo debajo de la novela visible que el lector tiene en sus manos.

¿De qué se trata, de qué se trataría esa otra novela sugerida por la novela que uno lee? Justamente de la historia misteriosa del tío de Renzi, de cuya desaparición sin rastros circulan múltiples versiones familiares. Renzi nos cuenta (en Respiración artificial):

No podía menos que atraerme el aire faulkneriano de esa historia: el joven de brillante porvenir, recién recibido de abogado, que planta todo y desaparece; el odio de la mujer que finge un desfalco y lo manda a la cárcel sin que él se defienda o se tome el trabajo de aclarar el engaño. En fin, yo había escrito una novela con esa historia, usando el tono de Las palmeras salvajes; mejor usando los tonos que adquiere Faulkner traducido por Borges, con lo cual, sin querer, el relato sonaba a una versión más o menos paródica de Onetti. (15-16)

Esta es la trama de la imaginaria La prolijidad de lo real, pero también, en efecto, de la material Respiración artificial. Por lo menos, esta es la historia que sirve como punto de partida para Respiración artificial, la novela que incluye, de cierta manera, la historia de La prolijidad de lo real y todo lo demás que es visible en el texto (la correspondencia con el tío, la correspondencia del pasado sobre un porvenir posible; la segunda mitad de la novela con los largos diálogos sobre la tradición argentina mientras el tío, Marcelo, está presente pero desaparecido en un misterio que gira

1 En el Prólogo a El jardín de senderos que se bifurcan, Borges dice "Desvarío laborioso y empobrecedor el de componer vastos libros; el de explayar en quinientas páginas una idea cuya perfecta exposición oral cabe en pocos minutos. Mejor procedimiento es simular que esos libros ya existen y ofrecer un resumen, un comentario" (429).

Revista Iberoamericana, Vol. LXXXIII, Núm. 258, Enero-Marzo 2017, 73-86 ISSN 0034-9631 (Impreso)

ISSN 2154-4794 (Electrónico) 
no sólo en torno a la historia familiar, sino en torno a la historia de todo el país). Es decir, si bien La prolijidad de lo real es una novela apócrifa de Renzi, La prolijidad de lo real está también presente -si bien invisible; casi invisible- en la Respiración artificial que uno lee.

Un par de años antes de la publicación de Respiración artificial, en uno de los primeros números de Punto de vista, Ricardo Piglia publica un relato titulado "La prolijidad de lo real". El breve cuento es básicamente una temprana versión del comienzo de Respiración artificial. ${ }^{2}$ La mayoría de los elementos de la novela que será Respiración artificial ya están ahí: el narrador Renzi y el misterio de su tío, el enganche que llevará a las cartas de la novela, las conexiones con el siglo XIX y los guiños al presente argentino del momento. También en el texto publicado en Punto de vista, el disparador para la reconexión entre tío y sobrino es la reciente publicación de una novela de Renzi (que Marcelo lee y que lo impulsa a escribirle la primera carta). Como en Respiración artificial, Renzi admite que había escrito una novela abiertamente faulkneriana: "Usando el tono de Las palmeras salvajes, esto es, usando los tonos que adquiere Faulkner traducido por Borges, con lo cual, sin querer, el relato sonaba a una versión más o menos paródica de Onetti" ("La prolijidad de lo real" 27). A lo cual le sigue la primera frase de la supuesta novela de Renzi. En Respiración artificial, Renzi dice "Hoy lo único que me gusta de ese libro es el título (La prolijidad de lo real) y el efecto que produjo en el hombre al que, sin querer, le estaba dedicado" (Respiración artificial 16). Pero en "La prolijidad de lo real", es decir en el relato de ese nombre publicado en Punto de vista, Renzi dice: "Hoy lo único que me gusta de ese libro es el título (Respiración artificial) y el efecto que produjo en el hombre al que, sin querer, le estaba dedicado" ("La prolijidad de lo real" 27).

En el relato "La prolijidad de lo real", entonces, se encuentra una referencia a una novela ficticia (Respiración artificial) escrita por el personaje Emilio Renzi. En la publicación del relato, Respiración artificial es citada como una novela imaginada, una ficción proyectada en una biblioteca invisible. Después, cuando leemos la novela Respiración artificial, encontramos casi la misma referencia a una novela imaginada, otra vez escrita por Emilio Renzi, pero esta vez titulada La prolijidad de lo real. La inversión es perfecta, y llamativa. Estamos frente a un juego con espejos que se desplazan, ${ }^{3}$ y también en un manual de literatura potencial. Emilio Renzi, protagonista en estos textos de Piglia, es también el pseudónimo que Piglia había usado para firmar textos que él publica en los primeros números de Punto de vista. Pseudónimo y, a la vez,

2 El relato publicado en Punto de vista contiene varias "ligeras variantes" a la versión que dos años más tarde será el comienzo de la novela Respiración artificial, como explica Edgardo Horacio Berg en "La novela que vendrá" (33).

3 Para decirlo con la formulación del narrador de "El acercamiento a Almotásim".

Revista Iberoamericana, Vol. LXXXIII, Núm. 258, Enero-Marzo 2017, 73-86 ISSN 0034-9631 (Impreso) 
protagonista y narrador de la ficción, aparente portavoz del autor, el papel y la función de Renzi se multiplican en esta época, entre Nombre falso y Respiración artificial. ${ }^{4}$

El procedimiento narrativo en estos textos crea una extraña y vertiginosa analogía y yuxtaposición entre Respiración artificial y La prolijidad de lo real. Como si cualquiera de los dos, como si los dos, fueran escritos de Piglia. O de Renzi. Emilio Renzi: más que un pseudónimo, más que un personaje ficticio, un doble que es y no es Piglia, confusión y difusión deliberada de la autoría y la subjetividad. ${ }^{5}$ Emilio Renzi, narrador y personaje de la primera parte de Respiración artificial, personaje de la segunda parte de Respiración artificial y actor en múltiples textos de Piglia (a veces pero no siempre como narrador); Renzi, cronista del diario El mundo, investigador y detective, escritor de la olvidada novela La prolijidad de lo real, es el nombre falso, como quien dice, del escritor Ricardo Piglia. Pero Renzi funciona porque también es un personaje, un personaje de ficción que escribe ficción (entre otras cosas) y una de sus publicaciones es la novela La prolijidad de lo real. Sin embargo, si bien el personaje ficticio Renzi hace varias referencias, en diferentes textos, a su novela La prolijidad de lo real, de rigor la novela La prolijidad de lo real no existe en nuestro mundo. Pero mejor sería decir que La prolijidad de lo real no es visible en nuestro mundo; La prolijidad de lo real sería parte de la biografía del personaje ficticio Emilio Renzi. Pero también se podría pensar que La prolijidad de lo real existe del mismo modo en el que existe la novela The Approach to Al'Mutasim: invisible pero presente, sugerida en la ficción, literatura conceptual en una biblioteca proyectada en la imaginación del lector. Se trata de literatura potencial, imaginada por un lector en la lectura de otro, con la posibilidad de afectar el presente desde el porvenir de un pasado re-pensado en la literatura.

El antecedente de Borges, ya se ve, es importante aquí. Recordemos, para matizar, la maniobra conceptual de Borges hacia el final de "Examen de la obra de Herbert Quain", cuando el narrador dice que él mismo ha extraído el argumento de "Las ruinas circulares" de un libro de Herbert Quain. El texto dice:

[Quain] afirmaba también que de las diversas felicidades que puede ministrar la literatura, la más alta era la invención. Ya que no todos son capaces de esa felicidad, muchos habrán de contentarse con simulacros. Para esos "imperfectos escritores", cuyo nombre es legión, Quain redactó los ocho relatos del libro Statements. Cada uno de ellos prefigura o promete un buen argumento, voluntariamente frustrado por el autor. Alguno - no el mejor- insinúa dos argumentos. El lector, distraído por la vanidad, cree haberlos inventado. Del tercero, The Rose of Yesterday, yo cometí la ingenuidad

4 Por otro lado, en plena dictadura, como destaca Laura Demaría, Piglia se enfrenta a "la prolijidad impuesta" con los elementos más sofisticados de la literatura argentina, es decir de la literatura, para imaginar, quizás, "la sociedad del porvenir" (Demaría 69).

5 Como dice Julio Premat, "Crítico, detective, testigo, se trata de un doble transparente del autor" (128).

Revista Iberoamericana, Vol. LXXXIII, Núm. 258, Enero-Marzo 2017, 73-86 
de extraer "Las ruinas circulares", que es una de las narraciones del libro El jardin de senderos que se bifurcan. (464)

Según esta ficción, el relato visible de Borges ("Las ruinas circulares") surgiría, es derivado de un libro invisible (The Rose of Yesterday), escrito, para así decir, por un personaje ficticio (Herbert Quain) del mismo Borges. La circularidad aquí se extiende de la ficción a su propia creación: El jardín de senderos que se bifurcan, se sugiere, contiene tanto los relatos del libro que leemos como los que el texto sugiere que existen, esa otra literatura imaginada (secreta e invisible). El jardín de senderos que se bifurcan es, de este modo, tanto un libro de relatos existentes (visibles, editados) como un libro de relatos inexistentes (invisibles, inéditos). He ahí, se podría decir, el elemento más fantástico de la literatura fantástica de Borges.

No menos fantástico, en este sentido, o conceptual, el trabajo que despliega Piglia con su personaje Renzi a lo largo de su vida. La potencialidad de la función de Renzi es llevada más lejos en Prisión perpetua (1988), nouvelle que narra, entre otras cosas, la historia del comienzo de la escritura del Diario de Renzi -historia que coincide con la del comienzo de la escritura del Diario de Piglia. Prisión perpetua, además, revela la aparente relación entre la lectura de la experiencia, la escritura del Diario, y la escritura de la ficción; es decir, la maquinaria narrativa que nutre a la escritura -aunque resulta imposible decir si se trata de la escritura de Renzi o la de Piglia. Renzi cuenta que vive la mudanza de su familia de Adrogué a Mar del Plata en su adolescencia como un "destierro" y que en esos días (de 1957) empieza a escribir un Diario -Diario que todavía mantiene más de 55 años más tarde, nos imaginamos, si seguimos el paralelo entre la cronología de Renzi y la de Piglia.

Prisión perpetua incluye ejemplos del Diario de Renzi, en forma de citas de este, y más adelante relatos y micro-historias cuya primera versión habían aparecido en los ejemplos del Diario anteriormente citados. Uno lee, por ejemplo, un fragmento con un comentario sobre el matrimonio, en la cita proveída del Diario de Renzi (Prisión perpetua 32) y, más adelante, otra versión del mismo comentario, ahora en el contexto del relato, "El fluir de la vida" (Prisión perpetua 70). Se puede decir, entonces, que "El fluir de la vida" narra la historia que narra y provee un ejemplo del procedimiento narrativo que va de la experiencia (de la lectura de la experiencia), a la escritura del Diario, a la escritura de la ficción en Prisión perpetua -todo en un mismo texto.

El efecto del Diario en Prisión perpetua se magnifica si pensamos al Diario de Renzi superpuesto al Diario sobre el cual Piglia ha hablado (y del cual ha publicado algunas pocas entradas) a lo largo de los años. En una estrechez sorprendente, Renzi se identifica casi enteramente con la escritura de su Diario y al hacerlo emerge literalmente como

Revista Iberoamericana, Vol. LXXXIII, Núm. 258, Enero-Marzo 2017, $73-86$ ISSN 0034-9631 (Impreso)

ISSN 2154-4794 (Electrónico) 
un personaje textualizado. El personaje escritor es lo que escribe en el Diario y lo que se escribe en el Diario es el personaje: "Hablar de mí," dice Renzi en Prisión perpetua, "es hablar de ese Diario. Todo lo que soy está ahí pero no hay más que palabras" (17). De un modo análogo, Piglia declara, recientemente: "Empecé a escribir un diario a fines de 1957 y todavía lo sigo escribiendo. Muchas cosas cambiaron desde entonces, pero me mantengo fiel a esa manía" ("Los Diarios de Ricardo Piglia”).

Pero, ¿qué es, precisamente, el Diario de Renzi? ¿Dónde está? ¿Quién lo tiene, dónde y cómo se lo puede leer? Sólo ocasionalmente vemos (entrevemos) fragmentos de este-alusiones, referencias, alguna que otra cita- en la obra de Piglia, y nunca tanto como en lo relativamente poco que aparece citado, fragmentado, en Prisión perpetua. En este sentido, se podría decir que el Diario de Renzi también es invisible - más bien, que el Diario de Renzi es casi invisible, porque lo vemos en partes (los fragmentos del Diario citados en el texto) y porque intuimos que hay más. El Diario de Renzi está sugerido en la obra de Piglia y es accesible sólo a través de una lectura entre líneas de los libros visibles que tenemos en su materialidad.

Por un lado, lo que decimos del Diario de Renzi probablemente se pueda decir, también, del Diario de Piglia. Por lo menos en este momento. Entonces, si el Diario de Renzi es (casi) invisible, ¿qué se puede decir del Diario de Piglia? ¿No sería (casi) invisible también? ¿Qué significa escribir, en vida, un libro póstumo, que nunca se termina de escribir y del cual apenas se editan algunas pocas muestras ocasionales? En efecto, nunca está más cerca Piglia a su personaje Renzi que en la concepción -y quizás en la creación- del Diario, donde parecería forjarse el material crudo -pero que también resulta ser parte esencial de la versión final- de la literatura del porvenir a la cual Piglia hace referencia en diferentes ocasiones y que se entrevé en sus textos. "La literatura es una forma privada de la utopía", leemos con Renzi, con Piglia, en Prisión perpetua (16).

El acontecimiento principal en la vida de Renzi en esa época, en el comienzo de la escritura (y a la vez el acontecimiento principal registrado en su Diario, como nos cuenta el texto), después de la mudanza de Adrogué a Mar del Plata, es conocer a Steve Ratliff, un norteamericano desterrado que vive en la Argentina y se convierte en una especie de padre, o mentor literario para Renzi. En Prisión perpetua se aclara, también, que Renzi es un tipo de investigador (detective, periodista, o escritor-es decir, un lector crítico), que descubre su función como testigo y cronista de la historia a su alrededor y que busca métodos para narrar las historias que otros no logran o no han podido narrar. "Invisible en el recuerdo, soy el que mira la escena" (Prisión perpetua 18) dice Renzi cerca del principio y, cuando está listo para narrar la historia de Steve Ratliff (aunque en efecto ya viene narrándola), agrega: "No importa quién habla. Soy el que puede decir lo que él dijo" (65). Aquí, en Prisión perpetua, el narrador Renzi es un cronista e investigador, a la vez testigo y portavoz de la historias de otros. Pero el

Revista Iberoamericana, Vol. LXXXIII, Núm. 258, Enero-Marzo 2017, 73-86 ISSN 0034-9631 (Impreso) 
papel creador -o recreador, si se quiere- del narrador es revelado en el mismo texto, en las transformaciones de citas fragmentarias del Diario, a micro-historias del texto, que después pueden circular, en este o en otros textos. ${ }^{6}$

Uno de los aspectos más curiosos de Prisión perpetua, por otro lado, es que Renzi narra, literalmente, como si lo que está narrando estuviera en inglés, aunque de rigor lo que nosotros leemos está en castellano. ${ }^{7}$ Hablando de Steve Ratliff, Renzi dice: "Sin él yo no sería un escritor; sin él yo no habría escrito los libros que escribí. Por él conocí la literatura norteamericana y por él me puse a aprender la lengua en la que estoy hablando con ustedes" (19). El texto entero se presenta como un problema de literatura potencial: leemos un texto desterrado de su original como si hubiera sido traducido, suponemos, del inglés al castellano en algún momento de su redacción, y que parecería anticipar, desde ya, su traducción eventual al inglés. El texto mismo parecería sugerir que traducir Prisión perpetua al inglés sería traducirlo devuelta al inglés, aunque este no sería el caso. Dicho de otra manera: en Prisión perpetua hay una traducción invisible que sólo se hace, se hará visible (aunque sea parcialmente, aunque sea casi visible) en su traducción futura. Hay algo en Renzi aquí -en la narración de su comienzo como escritor, el comienzo de su Diario y su encuentro con Steve Ratliffque parecería estar muy cerca al inglés, literariamente. No en la construcción de su escritura, ni la sintaxis, ni el léxico, ni el tono, todos elementos claramente argentinos en el texto de Piglia. Más bien, en el modo de pensar -como si pensar tuviera modos diferentes en diferentes lenguas y como si esto sí se pudiera traducir, en una traducción conceptual, quizás. Por momentos, en Prisión perpetua como en otros textos de Piglia, Renzi leans toward English.

La literatura potencial de Renzi en Piglia subraya las filiaciones inesperadas, las desviaciones creadoras y apunta, una vez más, al papel central de la traducción en la tradición argentina. No es una casualidad que parte de la formulación de La prolijidad de lo real incluya a la traducción y en particular a las ideas de la traducción desviada, las ideas de la (mal)traducción de Borges - como en el caso de Borges traductor de Faulkner, el ejemplo utilizado por Piglia en Respiración artificial / La prolijidad de lo real.

En “¿Existe la novela argentina?”, un ensayo sobre Borges y Gombrowicz, en diálogo explícito con "El escritor argentino y la tradición”, Piglia dice, "Los mecanismos de falsificación, la tentación del robo, la traducción como plagio, la mezcla, la combinación

6 Este procedimiento narrativo encontrará su representación casi perfecta, en Piglia, en la máquina en el Museo de La ciudad ausente.

Aspecto más que curioso, de paso sea dicho, para el que traducirá Prisión perpetua al inglés.

Revista Iberoamericana, Vol. LXXXIII, Núm. 258, Enero-Marzo 2017, 73-86 ISSN 0034-9631 (Impreso)

ISSN 2154-4794 (Electrónico) 
de registros, el entrevero de filiaciones. Esa sería la tradición argentina" (14). Aquí, Piglia hace explícito el valor, la potencia, de "... la traducción como plagio...". Siguiendo a Borges (pero también a Gombrowicz y a Arlt, en un cruce ya paradigmático en Piglia), el argumento no sólo no niega que la traducción sea un plagio, sino que la valora precisamente por su método intrínseco de apropiación y transformación. Como la falsificación y el robo, "la traducción como plagio" tendría el potencial de producir una mezcla que des-purifica. Se trata de la traducción equívoca, desviada; como la lectura desviada del misreading, ${ }^{8}$ se trata del mistranslation (la maltraducción) de la tradición argentina. Los misreadings y mistranslations que forman a la tradición argentina y los misreadings y mistranslations que se forman en la tradición argentina.

\section{IV}

¿Cómo se lee un misreading? ¿Cómo se traduce una mistranslation? ¿Cómo viaja una tradición atravesada por tantos viajeros? Pasamos en esta sección a una escena casi invisible de traducción como una posible indagación de las implicaciones del lugar de "la traducción como plagio" en la tradición argentina, y de nuestra relación con ella. El ejemplo puntual es una reciente traducción al inglés del relato que sirve como "Prólogo" a El último lector de Piglia.

En un ensayo sobre los "Itinerarios de lectura (y escritura)" en Piglia, Rose Corral analiza los espacios y la ciudad en la obra de este autor. Su artículo incluye una parte importante sobre el "Prólogo" de El último lector. En este relato/prólogo el narrador (que podría ser Piglia, ya que es el prólogo de un libro de ensayos, pero también podría ser Renzi, como se verá) cuenta que hay un fotógrafo en Flores, llamado Russell, que ha construido la réplica de una ciudad, una versión en miniatura perfecta de Buenos Aires, "una máquina sinóptica: toda la ciudad está ahí, concentrada en sí misma, reducida a su esencia" (El último lector 11). El narrador visita al fotógrafo de Flores; una vez ahí, le da una moneda griega que el fotógrafo sostiene y observa mientras el

8 El concepto de misreading utilizado a partir de la década de 1970 por Harold Bloom y otros críticos tiene su base, en la tradición anglo-americana, en los argumentos del influyente "Tradition and the Individual Talent" de T. S. Eliot, de 1919. En esta línea, Eliot declara que, "Los poetas inmaduros imitan, los poetas maduros roban; los malos poetas desfiguran lo que toman, y los buenos poetas lo convierten en algo mejor, o por lo menos en algo diferente. El buen poeta suelda su robo en una totalidad de sentimiento que es única, completamente diferente de la de donde fue desgarrada", traducción mía [Immature poets imitate, mature poets steal; bad poets deface what they take, and good poets make it into something better, or at least something different. The good poet welds his theft into a whole of feeling which is unique, utterly different from that from which it was torn] (The Sacred Wood 114). En este artículo, como en varios otros sitios, yo uso el término mistranslation en un sentido análogo. Traducir mistranslation al español no es obvio. La maltraducción sería algo así como la traducción equívoca, desviada, con el potencial de ser creadora y feliz.

Revista Iberoamericana, Vol. LXXXIII, Núm. 258, Enero-Marzo 2017, 73-86 ISSN 0034-9631 (Impreso)

ISSN 2154-4794 (Electrónico) 
narrador (Piglia/Renzi) observa la construcción de la ciudad; al final de la historia, el narrador deja la réplica en miniatura, el fotógrafo le devuelve la moneda griega, y el narrador vuelve a la ciudad.

Pensando en este texto, Rose Corral explica que para Piglia:

"El arte de narrar" es no sólo "un arte de la duplicación" (como las réplicas) sino también la posibilidad de ver mundos múltiples en el mapa mínimo de la ciudad o del lenguaje. La ciudad del fotógrafo [Russell] es un espacio que prefigura estos mundos y que también cuenta, como siempre en Piglia, otra trama, más secreta, que vincula la lectura con la memoria y con la tradición. (200)

Corral lee la relación entre el laboratorio del fotógrafo Russell, la habitación de las pensiones, y la versión microscópica de la ciudad y analiza la importancia de estos espacios privilegiados en la ficción de Piglia, especialmente eficaz en este texto al ser un laboratorio que contiene la construcción del modelo de la ciudad, un Aleph con diferencias. ${ }^{9}$

Hace poco me tocó preparar una traducción de este texto para una revista estadounidense (la Translation Review), donde se publicó como un relato de ficción de Piglia. Por un lado, el texto en traducción cambia de género. En El último lector el texto es un relato ficticio utilizado como Prólogo a un libro de ensayos, sugiriendo, quizás, que el texto está más cerca de la no-ficción, o que hay cierto contagio de la ficción en los ensayos que siguen. En la traducción en inglés, el texto publicado independiente de su libro original, es directamente un relato ficticio. Por otro lado, en la traducción el relato también cambia de título y con esto el texto pasa a conectarse con una serie subterránea de textos que forman parte de ambas la literatura visible e invisible en cuestión.

Al cambiar el contexto de la publicación, necesitábamos un título para el texto en inglés. Cuando le pregunté a Piglia al respecto, él sugirió “La construcción”, que funcionaría y es el título con el cual se ha publicado el relato en alemán. A mí me parecía que "The Construction" en inglés sonaba demasiado como una obra arquitectónica de trabajo, pero con más énfasis en la obra que en lo arquitectónico y en vez sugerí "The Structure". De hecho, el texto varias veces dice "la construcción" en referencia al modelo de la ciudad en miniatura de Russell, y en esos casos yo traduzco "la construcción" como "the structure". ${ }^{10}$ Otra opción podría haber sido "The Model", pero esto sonaba

9 Rose Corral observa que: "Hay un gesto característico en la obra de Piglia, un doble movimiento que permite, por un lado, leer 'en términos espaciales' la tradición literaria y, por otro, proyectar en su ficción espacios múltiples que funcionan también $[\ldots]$ en un doble registro, como espacios físicos y como metáforas del acto de narrar" (197).

10 "La construcción" del fotógrafo de Flores suena, por momentos, como el museo de Macedonio (en La ciudad ausente), o como una maqueta, en miniatura, de este. "La construcción" del fotógrafo de

Revista Iberoamericana, Vol. LXXXIII, Núm. 258, Enero-Marzo 2017, 73-86 ISSN 0034-9631 (Impreso)

ISSN 2154-4794 (Electrónico) 
menos ambiguo que "la construcción" que se encuentra en el centro del texto, en la orilla de la ciudad. También sugerí "The Synoptic Machine”, uno de los epitafios de la construcción de Russell, pero esto probablemente hubiera sido demasiado reductivo. Piglia finalmente propuso "The Greek Coin" y con este título lo publicamos en inglés. El título es bueno. En el texto se lee:

La diminuta ciudad es como una moneda griega hundida en el lecho de un río que brilla bajo la última luz de la tarde. No representa nada, salvo lo que se ha perdido. Está ahí, fechada pero fuera del tiempo, y posee la condición del arte, se desgasta, no envejece, ha sido hecha como un objeto precioso que rige el intercambio y la riqueza. (El último lector 13)

En una conversación sobre el tema, Piglia me contó por teléfono que había pensado escribir tres relatos, una especie de tríptico, conectados por el fluir de la misma moneda que manejan Renzi y Russell. Un personaje encuentra la moneda griega al final de "En noviembre", el relato enigmático de La invasión, donde nunca se dice por qué hay una moneda griega en un barco medio-hundido a tres kilómetros de la costa de Argentina; en el segundo relato, este personaje le daría la moneda a Renzi; y Renzi le traería la moneda a Russell, el fotógrafo de Flores, en el Prólogo a El último lector. El segundo relato de esta serie, de paso sea dicho, es un texto casi invisible: una vez más, en vez de escribirlo (por ahora), se simula que ya existe y se ofrece un resumen, un comentario y así, me gustaría pensar, se hace presente en la conversación entre dos y también, brevemente, al mencionarlo aquí.

La serie de historias narradas en la conversación telefónica explica de dónde viene la moneda griega que Renzi tiene para dársela al hacedor de la construcción, el fotógrafo de Flores, pero no por qué se la da o por qué este se la devuelve al final. Las historias circulan, el enigma persiste. La moneda griega se convierte en el agente de intercambio de los relatos, una construcción (la moneda) se intercambia por otra (el modelo de la ciudad en miniatura), un Aleph por otro. El destino de un hombre se determina en el lanzar al aire de una moneda antigua misteriosamente aparecida en los restos de un barco hundido a la vista de la costa argentina; el destino de una ciudad se decide en los detalles del modelo de la construcción secreta en el laboratorio de un fotógrafo perdido en un suburbio ordinario de Buenos Aires.

Flores hace eco, a la vez, con la fábrica en ruinas de Blanco nocturno en la cual Luca Belladona se dedica a trabajar la materia de sus sueños en un intento de producir objetos reales de la materia onírica. Recientemente terminé la traducción de un texto extraído de la segunda parte de Blanco nocturno; para su publicación en inglés la titulamos "The Factory". Esta versión de la fábrica, si bien en otra lengua, pertenece de cierto modo a la misma serie.

Revista Iberoamericana, Vol. LXXXIII, Núm. 258, Enero-Marzo 2017, 73-86 ISSN 0034-9631 (Impreso) 
La traducción, como sugiere Borges en "El enigma de Edward FitzGerald", es una colaboración misteriosa, a lo cual yo agregaría que la "fortuita conjunción" entre autor y traductor suele ser invisible y secreta. Mejor: casi invisible, casi secreta. La colaboración misteriosa, ya Borges lo sugiere, es menos una cuestión mística que matemática. Se trata de una escena conceptual, entrevista en la escena de traducción -como si uno pudiera rastrear allí ese otro texto previo que uno siente tiene que estar allí, que uno siente que tiene que haber estado allí. "Un escritor", dice Piglia, "trabaja en el presente con los rastros de una tradición perdida" ("Literatura y tradición" 59). No es tanto que la formulación se puede aplicar también a la traducción; más bien, la traducción ilustra la formulación de un modo directo. La traducción revela la relación que un lector (un escritor, un traductor) intenta crear con los restos que encuentra (que escaba) de una tradición en fuga. El traductor escribe, en otra lengua, su lectura del texto originario, y deja las marcas de su lectura, en esa otra lengua, para que un lector futuro lea el texto visible (la traducción) y se imagine un texto invisible (el original). El concepto de la fidelidad parecería quedarse afuera.

Pero la fidelidad no se queda afuera, no del todo. Más bien, el traductor siempre comete errores, la traducción es valiosa por lo que acierta y por lo que equivoca. (No es necesario cambiar de idioma para que se realice este posibilidad. Basta pensar en "Pierre Menard", como principio. Como principio básico, como primer principio, pensemos en "Pierre Menard"). Y hablamos de la (mal)traducción (mistranslation) no para condenar a la traducción sino para realizar su potencial, en el mismo sentido en que hablamos de la lectura desviada (misreading) como la manera de realizar el potencial de una lectura creadora. Como ha dicho Piglia, "Habría que reflexionar sobre qué quiere decir leer mal; qué tipo de efecto puede producir una lectura que se desvía de lo que en principio pueden ser los sentidos dados del texto" ("Romance e tradução"). Piglia hace este comentario recordando lo que dice Borges en varias ocasiones, que el primer libro que leyó fue el Quijote en inglés, y que cuando más tarde lo leyó en español le pareció una mala traducción. Piglia celebra la picardía de Borges, y propone que además de su característica agudeza Borges de hecho utiliza a la traducción como método disparador para investigar la potencialidad de lecturas productivas justamente por ser equivocadas. "Los libros recorren grandes distancias", agrega Piglia. "La traducción es el espacio de los grandes intercambios y de las circulaciones secretas" ("Romance e tradução").

En "Examen de la obra de Herbert Quain" de Borges, como vimos antes, leemos, "El lector, distraído por la vanidad, cree haberlos inventado". Lo mismo se puede decir del lector que se propone reescribir el texto en otra lengua. El traductor, que reescribe todo un texto que ya está escrito; el traductor, que narra historias de otros con sus

Revista Iberoamericana, Vol. LXXXIII, Núm. 258, Enero-Marzo 2017, 73-86 ISSN 0034-9631 (Impreso)

ISSN 2154-4794 (Electrónico) 
propias palabras pero las atribuye a otro (al autor, como corresponde); el traductor, cuya eficacia parecería medirse en su capacidad de desvanecerse, de irse hacia la imposible expectativa de la invisibilidad. "¿Qué es un 'nombre falso", pregunta Edgardo Horacio Berg, "sino la costura enigmática de los ancestros literarios, el 'block mágico' que inscribe al mismo tiempo, como un palimpsesto, la huella de lo escrito y su borramiento?" (32).

\section{CONCLUSIÓN}

¿Se puede leer la tradición argentina que realiza una serie de transformaciones, cruces, reescrituras, y mal-traducciones en su propia formación y desarrollo, afuera de la Argentina? ¿Se puede leer la tradición argentina afuera, a través de una reescritura a otra lengua -es decir, leerla a través de la traducción? Un lector de Borges que presta atención a la potencialidad de las "infidelidades creadoras" de este u otro escritor: ¿puede tal lector reescribir este concepto, el concepto de la traducción desviada (i.e., la teoría de la "mis-translation" "11), en inglés, en el Norte, cuando se sienta a traducir a Ricardo Piglia, por ejemplo? ¿Cuáles son las implicaciones de las teorías de Borges de la mal-traducción para la lectura de la literatura argentina -0 , más ampliamente, la literatura latinoamericana- ella misma en traducción? Preguntas para otro ensayo, quizá, pero también preguntas con las cuales terminar este: porque traducir es muy parecido a escribir leyendo otra literatura, sugerida como contra la corriente, secreta y postulada para otro día. Otra versión de la novela del porvenir. Leer la tradición de otro modo en búsqueda de la novela clandestina del porvenir: ¿qué mejor razón para emprender la tarea casi invisible del traductor?

Existe un paralelo conceptual entre la invisibilidad de la obra de Emilio Renzi y la invisibilidad de la traducción -en particular la invisibilidad de la traducción en el caso específico de la traducción al inglés de Ricardo Piglia. Porque la traducción lee un texto (el original, el visible) y produce un segundo texto (el texto meta, sugerido por el original) análogo al texto invisible, también sugerido por -y contenido en- el original. "Un escritor trabaja en el presente" dice Piglia, "con los rastros de una tradición perdida" ("Literatura y tradición" 59). Lo mismo podríamos decir de un traductor. Entrever en esos "rastros de una tradición perdida" la posibilidad de uno nuevo: traducir a Piglia resulta (traducir a Piglia ha resultado) como leer literatura casi invisible; en este caso, la obra (casi invisible) de Emilio Renzi. El traductor escribe no sólo lo que está presente (el texto visible), sino también lo que podría haber estado ahí: lo que se creía perdido pero ahora, de un modo completamente inesperado, y felizmente insólito,

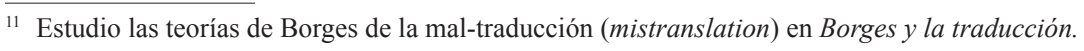

Revista Iberoamericana, Vol. LXXXIII, Núm. 258, Enero-Marzo 2017, $73-86$ ISSN 0034-9631 (Impreso) 
reaparece transformado en otra cosa, como el funcionamiento básico de la máquina de La ciudad ausente. ${ }^{12}$

Traducir a Piglia revela una potencialidad secreta y clandestina, como si fuera la potencialidad secreta y clandestina de la tradición misma: la obra invisible de Emilio Renzi apunta hacia esa otra tradición que siempre querríamos que alguien escriba. Traducir a Piglia, leer la obra invisible de Renzi: eventos que trazan el lugar de la novela del porvenir de esa tradición. Incierto casi por definición, ese sería el lugar de la tradición en Piglia -y en la traducción de Piglia: el "nombre falso" (Assumed Name) de la literatura argentina.

Cuando uno traduce, en el momento de traducir, uno habita dos lenguas, y dos identidades, aunque sea momentánea e inestablemente. Traducir, entonces, es pluralizarse. Ser más que uno es incómodo y así debería ser; es incómodo, difícil y precario, situarse en la frontera, en el límite, de las transformaciones necesarias para, y creadas por la traducción. El asunto con traducir a Piglia se complica (se ha complicado) porque al traducirlo a Piglia el traductor reescribe la lectura de un original que se sabe consciente del potencial de la traducción, un original que entiende que la escritura de la traducción intenta escribir la lectura de un texto que lee otros textos para poner sus lecturas en una circulación constante como parte de su maquinaria. La superposición entre tradición y traducción donde se pueda percibir el lugar, el potencial de una obra casi invisible. Casi.

${ }^{12}$ En La ciudad ausente se lee: "Primero habían intentado una máquina de traducir [...] Una tarde le incorporaron William Wilson de Poe para que lo tradujera. A las tres horas empezaron a salir las cintas de teletipo con la versión final. El relato se expandió y se modificó hasta ser irreconocible. Se llamaba Stephen Stevensen. Fue la historia inicial [...] Queríamos una máquina de traducir y tenemos una máquina transformadora de historias [...] Usa lo que hay y lo que parece perdido lo hace volver transformado en otra cosa. Así es la vida" (44-45).

Revista Iberoamericana, Vol. LXXXIII, Núm. 258, Enero-Marzo 2017, 73-86 ISSN 0034-9631 (Impreso) ISSN 2154-4794 (Electrónico) 


\section{BIBLIOGRAFÍA}

Berg, Edgardo Horacio. “La novela que vendrá: apuntes sobre Ricardo Piglia”. Ricardo Piglia: La escritura y el arte nuevo de la sospecha. Daniel Mesa Gancedo, ed. Sevilla: Secretariado de publicaciones, Universidad de Sevilla, 2006. 23-53.

Borges, Jorge Luis. Obras completas 1 y 2. Barcelona: Emecé Editores España, 1996. Corral, Rose. "Itinerarios de lectura (y escritura)". Entre ficción y reflexión: Juan José Saer y Ricardo Piglia. Rose Corral, ed. México: El Colegio de México, 2007. 193-205.

Demaría, Laura. "La prolijidad de lo real: el lugar del intelectual y de la crítica". Ricardo Piglia: una poética sin límites. Adriana Rodríguez Pérsico, ed. Pittsburgh, PA: Instituto Internacional de Literatura Iberoamericana, 2004. 65-82.

Díaz Quiñones, Arcadio. "La literatura de una nación pequeña: Juan José Saer y Ricardo Piglia”. Entre ficción y reflexión: Juan José Saer y Ricardo Piglia. Rose Corral, ed. México: El Colegio de México, 2007. 51-73.

Eliot, T.S. The Sacred Wood: Essays on Poetry and Criticism. New York: Alfred A. Knopf, 1921.

Piglia, Ricardo. La ciudad ausente. Buenos Aires: Editorial Sudamericana, 1992. "Los Diarios de Piglia, en Babelia”. El país (13 enero 2011). <http://blogs.elpais. com/papeles-perdidos/2011/01/los-diarios-de-piglia-en-babelia.html >.

“¿Existe la novela argentina?” Espacios de crítica y producción 6 (1987): 13-15. "The Factory, A Novel Excerpt by Ricardo Piglia". Sergio Waisman, trad. The Massachusetts Review LV/3 (Fall 2014): 348-65.

"The Greek Coin." Sergio Waisman, trad. Translation Review 77/78(2009): 72-76. "Literatura y tradición. El tenso músculo de la memoria”. Página 30 (enero 1991): 59-62.

"El lugar de Saer". El lugar de Piglia: Crítica sin ficción. Jorge Carrión, ed. Barcelona: Editorial Candaya, 2008. 162-88. Prisión perpetua. Buenos Aires: Editorial Sudamericana, 1988. "La prolijidad de lo real". Punto de vista 3 (julio 1978): 26-28. Respiración artificial. Buenos Aires: Pomaire, 1980.

"Romance e tradução (conferência de Ricardo Piglia)". Companhia das Letras.

São Paulo, Brazil. Septiembre 26, 2011. Conferencia y lectura. <http://www. blogdacompanhia.com.br/2011/09/dia-do-tradutor/>. El último lector. Barcelona: Anagrama, 2005.

Premat, Julio. "Los espejos y la cópula son abominables". Ricardo Piglia: una poética sin límites. Adriana Rodríguez Pérsico, ed. Pittsburgh: Instituto Internacional de Literatura Iberoamericana, 2004. 123-34.

Waisman, Sergio. Borges y la traducción: la irreverencia de la periferia. Buenos Aires: Adriana Hidalgo Editora, 2005.

Revista Iberoamericana, Vol. LXXXIII, Núm. 258, Enero-Marzo 2017, 73-86 ISSN 0034-9631 (Impreso) ISSN 2154-4794 (Electrónico) 